\title{
Feasibility of Laparoscopic Right Posterior Sectionectomy for Malignant Lesion Compared to Open Right Posterior Sectionectomy: Retrospective, Single Center Study
}

\author{
Eui Sung Jeong, M.D. ${ }^{1}$, Yang Seok Koh, M.D., Ph.D. ${ }^{2}$, Chol Kyoon Cho, M.D., Ph.D. ${ }^{2}$, Hee Joon Kim, M.D., Ph.D. ${ }^{3}$, \\ Eun Kyu Park, M.D., Ph.D. ${ }^{3}$ \\ 'Department of Surgery, Chonnam National University Hospital, Gwangju, 2Division of Hepatobiliary Surgery, Department of Surgery, Chonnam National \\ University Hwasun Hospital, Hwasun, ${ }^{3}$ Division of Hepatobiliary Surgery, Department of Surgery, Chonnam National University Hospital, Gwangju, Korea
}

Purpose: We aimed to compare the operative outcomes of laparoscopic right posterior sectionectomy (RPS) and open RPS and evaluate the feasibility of laparoscopic RPS.

Methods: From January 2009 to December 2017, laparoscopic liver resections were performed in 235 patients at Chonnam National University Hwasun Hospital, South Korea. We retrospectively analyzed the clinical data of 16 patients who underwent laparoscopic RPS and compared the outcomes with those who underwent open RPS ( $n=17)$.

Results: The laparoscopic group had a mean tumor size of $3.82 \pm 1.73 \mathrm{~cm}$ (open group [OG]; 4.18 \pm 2.07 $\mathrm{cm}, p=0.596)$, mean tumor-free margin of $10.44 \pm 9.69 \mathrm{~mm}(\mathrm{OG} ; 10.06 \pm 10.62 \mathrm{~mm}, p=0.657)$, mean operation time of $412.2 \pm 102.2 \mathrm{~min}(\mathrm{OG} ; 275.0 \pm 60.5, p<0.001)$, mean estimated blood loss of $339.4 \pm 248.3 \mathrm{ml}(\mathrm{OG} ; 236.4 \pm 102.7 \mathrm{ml}, p=0.631$ ), mean postoperative hospital stay of $11.63 \pm 2.58$ days (OG; 14.71 \pm 4.69 days, $p=0.027$ ), and mean postoperative peaks of aspartate aminotransferase, alanine aminotransferase, total bilirubin, and prothrombin time of $545 \mathrm{mg} / \mathrm{dl}, 538 \mathrm{mg} / \mathrm{dl}, 1.39 \mathrm{mg} / \mathrm{dl}, 1.41$ international normalized ratio (OG; 237 ( $p<0.001), 216(p<0.001), 1.52(p=0.817)$, and $1.45(p=0.468)$ ), respectively. There were no deaths or major complications in ether group. There were no cases of open conversion. Laparoscopic RPS was associated with a shorter hospital stay, prolonged operation time and lower complication rate. With long-term prognosis, no difference was found in overall survival rate and disease-free survival rate between the two groups.

Conclusion: Laparoscopic RPS can be performed, but the problems of long operative time and decrease in liver function should be resolved.

Keywords: Hepatectomy, Laparoscopy, Liver neoplasms

This is an Open Access article distributed under the terms of the Creative Commons Attribution Non-Commercial License (http:// creativecommons.org/licenses/by-nc/4.0/) which permits unrestricted non-commercial use, distribution, and reproduction in any medium, provided the original work is properly cited.
Received September 4, 2019

Revised October 17, 2019

Accepted November 4, 2019

Corresponding author

Yang Seok Koh

Division of Hepatobiliary Surgery, Department of Surgery, Chonnam

National University Hwasun

Hospital, 322 Seoyang-ro, Hwasuneup, Hwasun 58128, Korea

Tel: +82-62-220-6456

Fax: +82-62-220-6456

E-mail: bleocrj@hanmail.net ORCID:

https://orcid.org/0000-0002-0368-5389

\section{INTRODUCTION}

Laparoscopic hepatectomy has evolved significantly in the past decades. Limited laparoscopic hepatectomy for peripheral lesions is considered safe for both benign and malignant le- sions of the liver, owing to lesser bleeding, fewer complications, better cosmetic results, and better quality of life compared to open hepatectomy. ${ }^{1-4}$ Oncological outcomes in overall and disease-free survivals with laparoscopic hepatectomy and open surgery are comparable for hepatocellular carcinoma and 
colorectal cancer liver metastasis. ${ }^{5-8}$ Currently, laparoscopic left lateral sectionectomy is the routine method, but recommendations suggest that major hepatectomy should be performed only by experienced surgeons. ${ }^{1}$ In particular, because of technical difficulties in full liver mobilization and effective traction to well-visualize the resection plane in laparoscopic resection of tumors located in the right posterior lesion, laparoscopic right posterior sectionectomy (RPS) is rarely performed. ${ }^{9-12}$ A few case series of laparoscopic RPS have been reported. The purpose of this study was to compare the operative outcomes of laparoscopic RPS with those of open RPS and evaluate the feasibility of laparoscopic RPS.

\section{MATERIALS AND METHODS}

\section{Study population and data source}

We retrospectively reviewed medical charts of 235 patients who underwent a laparoscopic liver resection at Chonnam $\mathrm{Na}^{-}$ tional University Hwasun Hospital, South Korea in the period from January 2009 to December 2017. We analyzed the clinical data of 16 patients who underwent laparoscopic RPS and compared the outcomes with those who underwent open RPS ( $n=17)$. All elective liver surgeries were performed by surgeons with over 10 years of experience. The baseline characteristics of patients who were evaluated included age, sex, body mass index (BMI), preoperative American Society of Anesthesiologist (ASA) class, and liver cirrhosis.

Data on the patients' clinicopathological characteristics, operative procedures, and postoperative outcomes were retrospectively collected from the medical records. Postoperative complications were defined as those that developed within 30 postoperative days, and were divided into local and systemic complications based on the development site. The severity was graded based on the Clavien-Dindo classification of surgical complications. This study was approved by the Institutional Review Board of Chonnam National University Hwasun Hospital.

\section{Operation indication and technique}

The indications for laparoscopic RPS were similar to those for open RPS. Tumors invading or adjacent to the main portal pedicle or inferior vena cava and central lesions in the suprahepatic junction adjacent to major hepatic vein were considered a contraindication.

We followed the procedure described in previous study on laparoscpic RPS. ${ }^{9} 13,14$ A pneumoperitoneum was established through a $10-\mathrm{mm}$ umbilical port and maintained below 12 mmHg. A flexible laparoscope was used. Initially, a cholecys- tectomy was performed in the usual manner. The liver was fully mobilized from the inferior vena cava, and multiple small hepatic veins were clipped and divided. Thereafter, the major Glissonian pedicle of the right posterior section was dissected and transected using an Endo-GIA stapler, which demarcated the right posterior section and this guided the plane of resection. The superficial hepatic parenchyma was transected using the Harmonic Scalpel (Ethicon, Cincinnati, OH, USA) along the demarcated line that was created by the ischemia and the deeper portion of the parenchyma was dissected using a laparoscopic cavitron ultrasonic surgical aspirator. Laparoscopic ultrasonography was used to localize the tumor and find its relationship with the major hepatic veins, for demonstration of any satellite nodule of HCC, and for helping achieve an adequate margin. The small branches of the hepatic veins were controlled with endoclips and the large branches of the right hepatic vein were transected with the Endo GIA. Once the specimen was completely detached, it was inserted into a protective bag. We usually extract the specimen through the incision created by extending the epigastric port site for large specimens.

\section{Statistical analysis}

Open RPS and laparoscopic RPS were compared using the appropriate statistical analyses. Numerical variables were expressed as mean \pm standard deviation or median and range and compared using the Student's t-test or Mann-Whitney U test, respectively. The patient survival was calculated by the product limit method of Kaplan and Meier, and the differences in the survival between the groups were compared using the logrank test. Two-sided $p$ values $<0.05$ indicated statistical significance. Statistical analyses were performed with SPSS 20.0 (SPSS Inc., Chicago, IL).

\section{RESULTS}

Table 1 summarizes the patient demographics for the open (OG) and laparoscopic groups (LG). A total of 33 patients (25 men and 8 women) underwent RPS during the study period. Sixteen patients (49.5\%) underwent laparoscopic RPS, while 17 (50.5\%) patients underwent open RPS. There were no significant differences in age $(59.7 \pm 8.3$ years in OG vs. $58.8 \pm$ 9.8 years in $L G, p=0.794)$, sex $(p=0.606)$, ASA class $(p=0.533)$, or BMI $\left(22.8 \pm 2.1 \mathrm{~kg} / \mathrm{m}^{2}\right.$ in $\mathrm{OG}$ vs. $24.8 \pm 3.51 \mathrm{~kg} / \mathrm{m}^{2}$ in $\mathrm{LG}$, $p=0.53)$. LG had a lower proportion of liver cirrhosis cases $(\mathrm{n}=5,31 \%)$ compared to OG $(\mathrm{n}=13,76 \%, p=0.025)$. There were no significant differences in the pathologic diagnosis or result. Pathologic diagnoses were hepatocellular carcinoma and cholangiocarcinoma in $16(94 \%)$ and 1 (6\%) patients, respectively, in 
Table 1. Demographic data and pathologic results of patients

\begin{tabular}{|c|c|c|c|}
\hline & $\begin{array}{c}\text { Open } \\
(n=17)\end{array}$ & $\begin{array}{l}\text { Laparoscopic } \\
\qquad(\mathrm{n}=16)\end{array}$ & $p$ value \\
\hline Age, year & & & 0.794 \\
\hline Mean \pm SD & $59.7 \pm 8.3$ & $58.8 \pm 9.8$ & \\
\hline Median (IQR) & $58(42 \sim 75)$ & $59(44 \sim 75)$ & \\
\hline Sex, n $(\%)$ & & & 0.606 \\
\hline Male & $12(70.6)$ & $13(81.3)$ & \\
\hline Female & 5129.4 & $3(28.7)$ & \\
\hline$A S A, n|\%|$ & & & 0.533 \\
\hline I & 1 (6) & $3(19)$ & \\
\hline$\|$ & $16(94)$ & $13(81)$ & \\
\hline III & $0(0)$ & $0(0)$ & \\
\hline BMI $\left(\mathrm{kg} / \mathrm{m}^{2}\right)$, mean \pm SD & $22.8 \pm 2.1$ & $24.8 \pm 3.5$ & 0.53 \\
\hline Liver cirrhosis, n (\%) & $13(76)$ & $5(31)$ & 0.025 \\
\hline Pthologic diagnosis, n (\%) & & & 0.533 \\
\hline Heatocellular carcinoma & $16(94)$ & $13(81)$ & \\
\hline Cholangiocarcinoma & $1(6)$ & 0 & \\
\hline Colorectal cancer liver metasatis & 0 & $3(19)$ & \\
\hline \multicolumn{4}{|l|}{ Pathologic result } \\
\hline Tumor size $(\mathrm{cm})$, mean $\pm S D$ & $4.18 \pm 2.07$ & $3.82 \pm 1.73$ & 0.596 \\
\hline $\begin{array}{l}\text { Resection margin }(\mathrm{mm}) \text {, } \\
\text { mean } \pm \text { SD }\end{array}$ & $10.06 \pm 10.62$ & $10.44 \pm 9.69$ & 0.657 \\
\hline
\end{tabular}

$A S A=$ American Society of Anesthesiology; $S D=$ standard deviation; $\mathrm{IOR}=$ interquartile range; $\mathrm{BMI}=$ body mass index .

OG, and hepatocellular carcinoma and colorectal cancer liver metastasis in $13(81 \%)$ and $3(19 \%)$ patients, respectively, in LG $(p=0.533)$. The mean tumor size in OG and LG were 4.18 \pm 2.07 $\mathrm{cm}$ and $3.82 \pm 1.73 \mathrm{~cm}(p=0.596)$, and the mean resection margin in OG and LG were $10.06 \pm 10.62 \mathrm{~mm}$ and $10.44 \pm 9.69 \mathrm{~mm}$, respectively $(p=0.657)$ (Table 1$)$. There was one $\mathrm{R} 1$ resection (tumor free resection margin $<1 \mathrm{~mm}$ ) in $\mathrm{OG}$ and no in $\mathrm{LG}$.

Table 2 summarizes surgical outcome for the open (OG) and laparoscopic groups (LG). The operation time was significantly longer in LG $(412.2 \pm 102.2 \mathrm{~min})$ compared to OG $(275.0 \pm 60.5$ min, $p<0.001)$. There were no significant differences in the estimated blood loss $(236.4 \pm 102.7 \mathrm{ml}$ in $\mathrm{OG}$ vs. $339.4 \pm 248.3 \mathrm{ml}$ in LG, $p=0.631)$, peak total bilirubin $(1.52 \pm 0.56 \mathrm{mg} / \mathrm{dl}$ in $\mathrm{OG}$ vs. $1.39 \pm 0.39 \mathrm{mg} / \mathrm{dl}$ in $\mathrm{LG}, p=0.817$ ) or peak prothrombin time (international normalized ratio, $1.45 \pm 0.17$ in OG vs. $1.41 \pm 0.15$ in LG, $p=0.468$ ). Peak aspartate aminotransferase (AST $545 \pm$ $178 \mathrm{U} / \mathrm{L}$ vs. $237 \pm 115 \mathrm{U} / \mathrm{L}, p<0.001)$ and alanine aminotransferase (ALT; $538 \pm 263$ vs. $216 \pm 145 \mathrm{U} / \mathrm{L}, p<0.001$ ) levels were
Table 2. Surgical outcome

\begin{tabular}{|c|c|c|c|}
\hline & Open $(n=17)$ & $\begin{array}{l}\text { Laparoscopic } \\
\qquad(n=16)\end{array}$ & $p$ value \\
\hline Op time, mean $\pm S D$ & $275.0 \pm 60.5$ & $412.2 \pm 102.2$ & $<0.001$ \\
\hline Blood loss, mean $\pm S D$ & $236.4 \pm 102.7$ & $339.4 \pm 248.3$ & 0.631 \\
\hline $\begin{array}{l}\text { Hospital stay (POD), } \\
\text { mean } \pm S D\end{array}$ & $14.71 \pm 4.69$ & $11.63 \pm 2.58$ & 0.027 \\
\hline AST, peak (mg/dl) & $237 \pm 115$ & $545 \pm 178$ & $<0.001$ \\
\hline ALT, peak (mg/dl) & $216 \pm 145$ & $538 \pm 263$ & $<0.001$ \\
\hline T-bil, peak (mg/dl) & $1.52 \pm 0.56$ & $1.39 \pm 0.39$ & 0.817 \\
\hline PT, peak (INR) & $1.45 \pm 0.17$ & $1.41 \pm 0.15$ & \\
\hline
\end{tabular}

$S D=$ standard deviation; $P O D=$ postoperative day; $A S T=$ aspartate aminotransferase; $\mathrm{ALT}=$ alanine aminotransferase; INR = international normalized ratio.

higher in LG compared to OG. The mean duration of hospital stay after the surgery was shorter in LG (11.63 \pm 2.58 days) compared to OG (14.71 \pm 4.69 days, $p=0.027)$, which was statis ${ }^{-}$ tically significant (Table 2, 3).

Based on the Clavien-Dindo classification, there were two (5.8\%) complications (grade 2; urinary tract infection and wound infection) in OG and none (0\%) in LG. There was no mortality within 90 postoperative days in either group. Additionally, there were no cases of open conversion (Table 4).

Out of 33 patients, 29 were diagnosed with hepatocellular carcinoma (OG=16, LG=13). None of them receive Transcatheter arterial chemoembolization (TACE) before surgery. The mean follow-up period was 43.6 month for OG and 42.7 month for LG. The number of deaths in the follow-up period were 3 in OG and 1 in LG. Local recurrence rate were 6.3\% $(1 / 16)$ in OG and 7.7\% (1/13) in LG. A patient with local recurrence in OG underwent TACE and one in LG underwent 2nd operation. In terms of the long-term outcome, we found no differences in the patient survival rate and disease-free survival rate between the two groups (Fig. 1, 2).

\section{DISCUSSION}

While preserving the hepatic reserve function, to secure the tumor-free margin is extremely important. In order to make sure the tumor-free margin, we routinely use the laparoscopic ultrasound examination repeatedly during the operation. This also helps to identify unexpected satellite lesions and localize major vessels.

Despite the retrospective nature, this study shows that laparoscopic RPS is a feasible therapeutic option as an alternative to open RPS. Laparoscopic RPS was associated with shorter 
Table 3. Details of laparoscopic right posterior resection

\begin{tabular}{ccccccccccc} 
Case & Diagnosis & $\begin{array}{c}\text { Tumor } \\
\text { size (cm) }\end{array}$ & $\begin{array}{c}\text { Cirrhosis on } \\
\text { pathology }\end{array}$ & $\begin{array}{c}\text { Operative } \\
\text { time } \\
\text { (minutes) }\end{array}$ & $\begin{array}{c}\text { Blood } \\
\text { loss (ml) }\end{array}$ & $\begin{array}{c}\text { Blood } \\
\text { transfusion } \\
\text { (ml) }\end{array}$ & $\begin{array}{c}\text { Margin } \\
\text { (mm) }\end{array}$ & $\begin{array}{c}\text { Hospital } \\
\text { stay (days) }\end{array}$ & Complication Concersion \\
\hline 1 & HCC & 2.5 & No & 285 & 250 & 0 & 3 & 12 & No & No \\
\hline 2 & HCC & 2.8 & Yes & 570 & 650 & 320 & 25 & 9 & No & No \\
\hline 3 & HCC & 4.3 & No & 395 & 170 & 0 & 1 & 16 & No & No \\
\hline 4 & CLM & 4.2 & No & 255 & 150 & 0 & 15 & 7 & No & No \\
\hline 5 & HCC & 2 & Yes & 585 & 400 & 0 & 25 & 14 & No & No \\
\hline 6 & HCC & 3 & No & 365 & 100 & 0 & 5 & 10 & No & No \\
\hline 7 & HCC & 3.1 & No & 415 & 130 & 0 & 1 & 13 & No & No \\
\hline 8 & HCC & 2.8 & Yes & 470 & 180 & 0 & 1 & 10 & No & No \\
\hline 9 & CLM & 7 & No & 325 & 750 & 0 & 10 & 12 & No & No \\
\hline 10 & CLM & 0.5 & No & 360 & 150 & 0 & 20 & 10 & No & No \\
\hline 11 & HCC & 7 & No & 380 & 400 & 0 & 10 & 13 & No & No \\
\hline 12 & HCC & 4.1 & Yes & 425 & 150 & 0 & 1 & 13 & No & No \\
\hline 13 & HCC & 3 & Yes & 465 & 750 & 0 & 20 & 12 & No & No \\
\hline 14 & HCC & 5 & No & 380 & 130 & 0 & 25 & 16 & No & No \\
\hline 15 & HCC & 4.3 & No & 600 & 750 & 0 & 3 & 8 & No & No \\
\hline 16 & HCC & 5.5 & Yes & 400 & 320 & 0 & 2 & 11 & No & No \\
\hline
\end{tabular}

$\mathrm{HCC}=$ hepatocellular carcinoma; $C L M=$ colorectal cancer liver metastasis.

Table 4. Mortality and morbidity of patients

\begin{tabular}{lcc} 
& Open & Laparoscopic \\
\hline Mortality in 90 days, $\mathrm{n}(\%)$ & $0(0.0)$ & $0(0.0)$ \\
Morbidity & $2(11.8)$ & $0(0.0)$ \\
Clavien-Dindo grade II, n $(\%)$ & UTI : $1(5.8)$ & \\
& Wound infection $1(5.8)$ & \\
\hline
\end{tabular}

hospital stays and lower complication rates compared to the open method, and there were no significant differences in tumor-free resection margin, blood loss, postoperative peak total bilirubin level, or peak prothrombin time between the groups. There was a tendency for longer operative time and elevated AST and ALT (decreased liver function) in LG. These results are generally consistent with previous studies on laparoscopic RPS. ${ }^{15,16}$ Cho et al. reported that a mean operation time of $567 \mathrm{~min}$ (412 $\mathrm{min}$ in this study), mean duration of postoperative hospital stay of $10.6 \pm 4.8$ days (11.63 \pm 2.58 days in this study), and mean tumor-free margin of $3.0 \pm 5.8 \mathrm{~cm}$ (10.44 $\pm 9.69 \mathrm{~mm}$ in this study). ${ }^{16}$ Although the follow-up period was not long and there was loss to follow-up, no difference

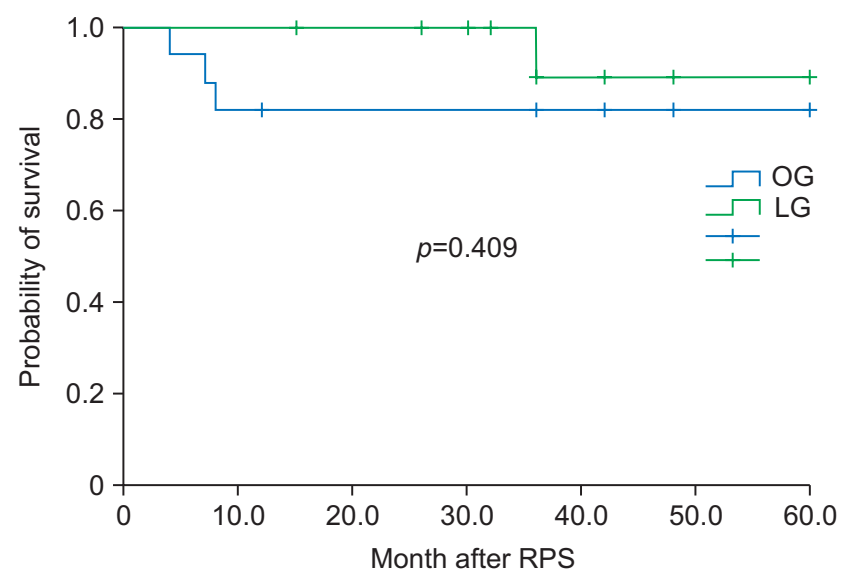

Fig. 1. Comparison of patient's survival rate between $O G$ and $L G$. No significant difference in survival rate was found between the two groups. $O G=$ open group; $L G=$ laparoscopic group.

was found in overall survival rate and disease-free survival rate between the two groups.

The present study has several potential limitations. First, it was a retrospective analysis conducted at a single center, so selection bias may exist in the results. Second, the sample size 


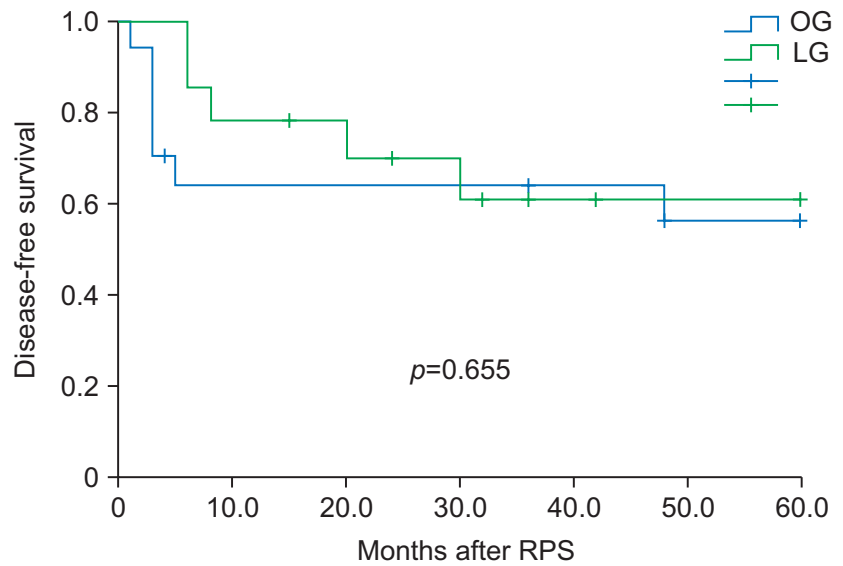

Fig. 2. Comparison of disease-free survival rate between $O G$ and $L G$. No significant difference in disease-free survival rate was found between the two groups. $O G=$ open group; $L G=$ laparoscopic group.

was relatively small ( $\mathrm{n}, \mathrm{LG}=16, \mathrm{OG}=17$ ). Therefore, there were deficiencies in gaining statistical power. Third, there was no accurate evaluation of oncological outcomes, such as diseasefree survival or overall survival, as more laparoscopic RPS has been performed relatively recently due to the operator's learning curve and there was no strict patient selection criteria.

Despite these limitations, this study has important implications. This is one of the few studies comparing laparoscopic RPS to open RPS at a single medical center. Thus, it provides an opportunity for a multicenter prospective cohort study to overcome these limitations in the future.

\section{CONCLUSION}

In conclusion, laparoscopic RPS is a possible surgical procedure in patients with a lesion in the right posterior region of the liver. We need to resolve the problems of long operative time and consequent decrease in liver function. Further studies with a larger number of patients and a longer follow-up period are required to evaluate the oncological outcomes.

\section{ORCID}

Eui Sung Jeong, https://orcid.org/0000-0003-4020-9311

Yang Seok Koh, https://orcid.org/0000-0002-0368-5389

Chol Kyoon Cho, https://orcid.org/0000-0001-8457-7314

Hee Joon Kim, https://orcid.org/0000-0002-8636-5726

Eun Kyu Park, https://orcid.org/0000-0001-7242-4855

\section{AUTHORS' CONTRIBUTIONS}

Conceptualization: CKC. Formal analysis: HJK. Methodol- ogy: EKP. Writing-original draft: ESJ. Writing-review and editing: YSK.

\section{CONFLICT OF INTEREST}

None.

\section{FUNDING}

None.

\section{ACKNOWLEDGMENTS}

None.

\section{REFERENCES}

1) Buell JF, Cherqui D, Geller DA, et al. The international position on laparoscopic liver surgery: The Louisville Statement, 2008. Ann Surg 2009;250:825-830.

2) Koffron A, Geller D, Gamblin TC, Abecassis M. Laparoscopic liver surgery: Shifting the management of liver tumors. Hepatology 2006;44:1694-1700.

3) Simillis C, Constantinides VA, Tekkis PP, et al. Laparoscopic versus open hepatic resections for benign and malignant neoplasms ${ }^{--a}$ meta-analysis. Surgery 2007;141:203-211.

4) Belli G, Fantini C, D’Agostino A, et al. Laparoscopic versus open liver resection for hepatocellular carcinoma in patients with histologically proven cirrhosis: short- and middle-term results. Surg Endosc 2007;21:2004-2011.

5) Shimada M, Hashizume M, Maehara S, et al. Laparoscopic hepatectomy for hepatocellular carcinoma. Surg Endosc 2001;15:541544.

6) Kaneko H, Takagi S, Otsuka Y, et al. Laparoscopic liver resection of hepatocellular carcinoma. Am J Surg 2005;189:190-194.

7) Ito $\mathrm{K}$, Ito $\mathrm{H}$, Are $\mathrm{C}$, et al. Laparoscopic versus open liver resection: a matched-pair case control study. J Gastrointest Surg 2009;13: 2276-2283.

8) Lee KF, Chong CN, Wong J, Cheung YS, Wong J, Lai P. Longterm results of laparoscopic hepatectomy versus open hepatectomy for hepatocellular carcinoma: a case-matched analysis. World J Surg 2011;35:2268-2274.

9) Casaccia M, Andorno E, Di Domenico S, et al. Laparoscopic right posterior sectionectomy for hepatocellular carcinoma using a modified liver-hanging maneuver. J Laparoendosc Adv Surg Tech A 2012;22:488-491.

10) Herman P, Kruger JA, Perini MV, Coelho FF, Lupinacci RM. Laparoscopic hepatic posterior sectionectomy: a hand-assisted approach. Ann Surg Oncol 2013;20:1266.

11) Tomishige H, Morise Z, Kawabe N, et al. Caudal approach to 
pure laparoscopic posterior sectionectomy under the laparoscopyspecific view. World J Gastrointest Surg 2013;5:173-177.

12) Herman P, Kruger J, Lupinacci R, Coelho F, Perini M. Laparoscopic bisegmentectomy 6 and 7 using a Glissonian approach and a half-Pringle maneuver. Surg Endosc 2013;27:1840-1841.

13) Yoon YS, Han HS, Choi YS, et al. Total laparoscopic right posterior sectionectomy for hepatocellular carcinoma. J Laparoendosc Adv Surg Tech A 2006;16:274-277.

14) Machado MA, Makdissi FF, Galvao FH, Machado MC. Intrahe- patic Glissonian approach for laparoscopic right segmental liver resections. Am J Surg 2008;196:e38-42.

15) Cheng KC, Yeung YP, Ho KM, Chan FK. Laparoscopic Right Posterior Sectionectomy for Malignant Lesions: An Anatomic Approach. J Laparoendosc Adv Surg Tech A 2015;25:646-650.

16) Cho JY, Han HS, Yoon YS, Choi Y, Lee W. Outcomes of laparoscopic right posterior sectionectomy in patients with hepatocellular carcinoma in the era of laparoscopic surgery. Surgery 2015;158: 135-141. 